\title{
Research of the English Network Teaching Resources System based on Data Warehouse Technology
}

\author{
Da LIU ${ }^{1,}$, Jingwei $\mathrm{SHU}^{2}$, Xueyan FAN ${ }^{3}$ \\ ${ }^{1,2,3}$ University of Science and Technology Liaoning, Anshan 114051,China \\ a zhuomuniaodolly@163.com
}

Keywords: Network teaching resources; English teaching; Warehousing technologies

\begin{abstract}
Build a platform of informationization as teaching auxiliary has become the mainstream teaching methods in all kinds of school under the network environment. It has the main target of the current middle school English teaching reform that involve various types of multimedia teaching resources into the junior middle school English classroom teaching, share teaching resources, stimulate students' interest in learning and change the traditional pattern of classroom teaching.
\end{abstract}

\section{The data warehouse and data warehouse}

So-called data warehouse is the process to build a data warehouse. Data warehouse does not mean database capacity is large enough to hold huge amounts of data, it not only store the data of data Warehouse, but help with data analysis of the on-line analytic processing (OLAP) and data mining (DM) tools, etc.

\section{Definition of data warehouse}

The concept of Data Warehouse is proposed by W.H. Inmon, vice President of Prism Solution company in the 1992. The proposal of Data Warehouse was based on the foundation of the rapid development of relational database, parallel processing and distributed technology, which is integrated solutions to solve the existing in the development of information technology with a lot of data and useful information on meager. [1]But as for what is a Data Warehouse, many people put forward different views.

W.H.Inmon defined data warehouse as: data warehouse is a data collection that subject-oriented, integrated, stable, change with time, which is used to support the operation and management in the decision making process.

Tim Shelter (vice President of Informix company): data warehouse integrate distributed information in the different island of enterprise network business data together, and store it in a single integrated relational database.

\section{Characteristics of the data warehouse}

There are several basic features in data warehouse in summary:

\section{1) Data warehouse is subject-oriented}

"Subject" conduct data integration, classification and analysis in a high level. Subject oriented data organization is object at a higher level of analysis of a complete, consistent, complete unity to depict the various enterprises involved in all kinds of data analysis object, and the relationships between data. Each topic basically corresponds a macroscopic analysis field.

\section{2) Data warehouse is integrated}

Data in data warehouse are extracted from the original distributed database data, the data are the results of operational data after cleaning. [2]Data must be processed before entering the data warehouse and integration, the unified data structure and encoding for different data sources, the original is the data for a shift from application oriented to subject oriented.

\section{3) Data warehouse data cannot be updated}

A large amount of historical data is contained in data warehouse, which seldom or never update under normal circumstances. Warehouse data not update relative OLTP data is from the perspective of the frequent change of operational data. It will put out the data from the data warehouse when data has exceed the capacity of data storage. 


\section{4) Data in warehouse data changes with time}

Data in warehouse data must constantly capture changes in the OLTP database and integrate them informally into the data warehouse. The data stored in data warehouse need to delete. A lot of comprehensive data in a data warehouse is related to time, these data need to change over time.

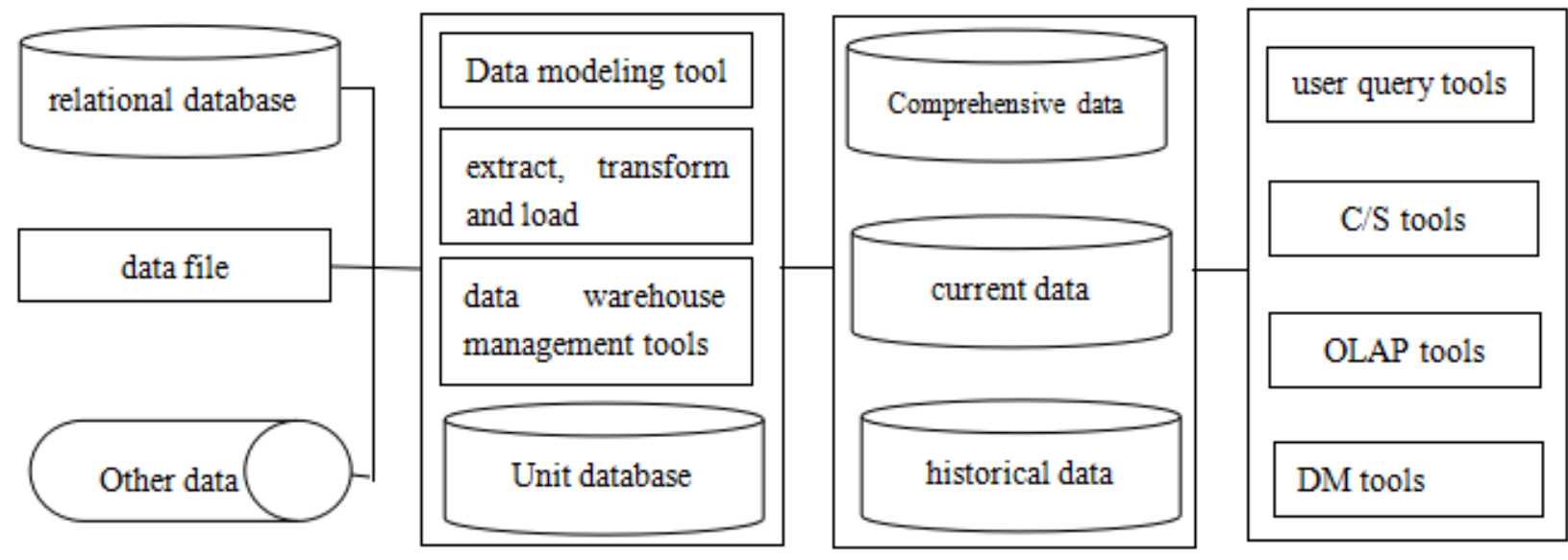

Figure1 system structure of data warehouse

\section{The network teaching}

Network teaching and its development status

Network teaching is teaching software system based on computer network environment, which can support teacher preparation, teaching and students' autonomous learning, carry out assignments, exams, online discussions, answering questions at any time.

Since the 1990s, information technology has developed rapidly in social fields. Use advanced information technology education reform and development of nature has become a major move around the world. Network education has the basic characteristics of breakthrough time and space limitation and realize resources sharing, leading to the sharing of education resources, expanding education resources, increasing the speed of education, promoting the education reform and other advantages, so the network teaching has become the important tendency of world education reform and development[3].

\section{Requirements of network teaching era}

The development of network teaching is with the development of multimedia technology and network technology and the teaching reform, which is a wave of also only a few years history in China. But, the network teaching system from the beginning, is attracting the attention of an education efforts, research trends was formed in just a year or two scale, it is enough to illustrate the development of network teaching in the present period has distinct era meaning.

The essential characteristics 21st century is the human society leap from industrial society to information society. The great changes not only changed the way human mode of production, work and lifestyle, and changed the way the human learning, such as reading tendency of hypermedia reading; writing tendency of hypermedia writing; high speed calculation tends to digital, etc. Obviously, modern information technology promote the change in the way human learning. The wide application of information technology, together with text production, the invention of printing is known as the three milestone in the development of learning style. Therefore, if have ability to access to information, analysis, processing and application of knowledge and information knowledge becomes the important measure of talent quality in information society.

\section{Characteristics of network teaching}

Network teaching not only changed the traditional teaching from means and form, it also gives new meaning to the teaching. Network teaching is different from traditional teaching, the teachers and students are the most fundamental characteristics.

Technically speaking, the network teaching is the purpose of computer network technology to 
serve the teaching, its implementation means is greatly superior to traditional teaching, which result in the different teaching ideas and methods.[4] But they both serve the purpose of teaching, network teaching evolves from traditional teaching and subjected to its ideas and methods.

From the implementation, traditional teaching take the classroom as environment, teaching notes as learning content, teachers take teaching, asking questions, the blackboard demo as the main way, assisted with charts, projection, video, and student work, discussion and test methods. The teachers play the role of a supervision and guidance in the teaching process.

\section{Data mining technology}

\section{Methods of data mining}

Data cleaning must be conducted in data mining to take out of abnormal data, and then do the data selection and integration, and change the data into a suitable for the type of data mining through data transform, the most important step is to select the appropriate data mining approach to find the rules in the data, finally show hidden data patterns and rules through the pattern evaluation and knowledge representation. The method of data mining mainly includes the following:

Classification and Prediction: Classification mining differentiate large amounts of data in accordance with the established model, the data can be classified into several categories. Prediction is to forecast the future development trend of data through the establishment of a continuous function model.

Clustering: Clustering mining is to divide into different categories according to instance attribute values automatically based on a set of data objects.

Association Rules: It is used to find relational data set useful to the user or meaningful connections hidden in the transaction data.

Time Series: It is the method to analyze the trend or change according to value of different time or series.

\section{Association rule mining}

Association rule Mining is looking for the same event correlation between different items. The mining strategy includes two aspects:

(1) Generation of Frequent item sets: look for all frequent item sets meet the minimum support threshold.

(2) Generation of rule: extract rules with high confidence level from the concentrated frequent items, these rules are called strong rules.

\section{Generation of frequent item sets}

Lattice Structure is often used to enumerate all possible item sets. Generally speaking, a data set contains d different item may be produced frequent item sets. R rule may be produced at the same time; which can be expressed in the following formula:

$$
R=\sum_{k=1}^{d-1}\left[\left(\begin{array}{l}
d \\
k
\end{array}\right) \times \sum_{j=1}^{d-k}\left(\begin{array}{c}
d-k \\
k
\end{array}\right)\right]=3^{d}-2^{d+1}+1
$$

(1) In ARMA model if the sequence is stable, normal, zero mean, set $X=\left\{x_{t} \mid t=0,1,2, \ldots, n-1\right\}$ and if the value of $\mathrm{X}$ in $\mathrm{t}$ time not only associates with its first $\mathrm{n}$ values $x_{t-1}, x_{t-2}, \ldots, x_{t-n}$, but also related to interference each step before $\mathrm{m} \alpha_{t-1}, \alpha_{t-2}, \ldots, \alpha_{t-m}$, according to the thought of multiple linear regression, moving average ARMA model can be obtained generally can be shown as:

$$
x_{t}=\sum_{i=1}^{n} \varphi_{i} x_{t-i}-\sum_{j=1}^{m} \theta_{j} \alpha_{t-j}+\alpha_{t}
$$

Among the type:

$$
\alpha_{t} \sim N I D\left(0, \delta_{a}^{2}\right)
$$

(2) AR model is a special case, if in the ARMA (n, m) model expression $\theta_{j}=0$, AR (n) model can be represented as: 
$x_{t}=\sum_{i=1}^{n} \varphi_{i} x_{t-i}+\alpha_{t}$

Among the type:

$\alpha_{t} \sim \operatorname{NID}\left(0, \delta_{a}^{2}\right)$

(3) MA model is another special case of ARMA model. If in the ARMA model expression $\varphi_{i}=0$, MA (m) model can be represented as:

$x_{t}=\alpha_{t}-\sum_{j=1}^{m} \theta_{j} \alpha_{t-j}$

Among the type:

$\alpha_{t} \sim N I D\left(0, \delta_{a}^{2}\right)$

\section{Web-based learning support system model}

\section{Advantages of web-based learning support system model}

Web-based learning support system (WBLSS) model was first put forward in 2000 by Chinese scholars Wu Fati in his doctoral thesis. The model is based on constructivist learning environment model of the American scholar David Jonasson. Relative advantage of the model is listed as follows:

Relative to the constructivist learning environment model, this model not only supports of a well-structured knowledge learning, also supports a well-structured knowledge learning.

Relative to the constructivist learning environment model, nine autonomous learning teaching strategies of the model can better support various learning activities.

The model is more focused on supporting for network learning environment, and it includes five basic elements of the network learning environment: intelligent teaching system based on Web, the repository system based on Web, the learning evaluation system based on Web, Web based communication and collaboration system, auxiliary tool system based on Web. [5]The five basic elements of each subsystem is a function, the organic integration constituting a network teaching system.

\section{Significance of Web-based learning support system model}

Support of Web-based learning support system model for autonomous learning and active learning is comparatively bigger. Architecture design will be set up in theory with emphasis on the college English autonomous learning function of network teaching system. Under the guidance of the model, this research promote students autonomous learning environment, active learning motivation in students' internal design. And provides sufficient support and auxiliary through reasonable feature set and the appropriate teaching strategies for students learning English in students' external design.

\section{Summary}

In modern society, high quality and efficiency of education has become a study of common requirements with a surge of knowledge information. The organic integration of teaching theory and network technology gave birth to network teaching. It can supplement daily teaching and also can exist independently, which also can effectively improve the teaching efficiency and effect. So it get more and more widely used in the teaching activity. To save teachers from heavy repetitive work, so that they can have more attention and pure force to improve the quality of teaching activities, one of effective way is to use computer technology to provide an auxiliary platform to support for their network teaching.

\section{Acknowledgements}

The project of Liaoning Education Teaching Reform No. UPRP20140457. 
Title: The Research and Practice of English Course for the Students of Engineering Majors with the International Background

\section{References}

[1] Symeon Retalis, \&Emanuel Skordalakis. CADMOS:An Approach to Developing Web-based Instructional Systems, Computers in Human Behavior, 17(4),393-407.

[2] Yair, Levy. Assessing the Value of E-Learning Systems. Hershey, Pennsylvania: Information Science Publishing, 2006.

[3] Dias J. Sovereign Debt Crisis in the European Union: A Minimum Spanning Tree Approach[J]. Physica A: Statistical Mechanics and Its Applications, 2012, 391(5): 2046-2055

[4] Xiao huaHu, Nick Cereone. Data Mining via Discretization, Generalizaion and Rough Set Feature Selection. Knowledge and Information Systems.1999,J.1(l):33-60.

[5] Zohra Bellahsene. Sehema Evolution in Data Warehouses. Knowledge and Information Systems. 2002,J.4(3):274-293. 